\title{
Exacerbations of COPD
}

This article was published in the following Dove Press journal:

International Journal of COPD

19 February 2016

Number of times this article has been viewed

\author{
Ian D Pavord' \\ Paul W Jones ${ }^{2}$ \\ Pierre-Régis Burgel ${ }^{3}$ \\ Klaus F Rabe 4,5 \\ 'Respiratory Medicine Unit, Nuffield \\ Department of Medicine, University \\ of Oxford, Oxford, UK; ${ }^{2}$ Division \\ of Clinical Science, St George's, \\ University of London, London, UK; \\ ${ }^{3}$ Department of Respiratory Medicine, \\ Cochin Hospital, University Paris \\ Descartes, Sorbonne Paris Cité, Paris, \\ France; ${ }^{4}$ Department of Medicine, \\ Christian Albrecht University, Kiel, \\ Germany; ${ }^{5}$ LungenClinic, Member \\ of the German Center for Lung \\ Research (DZL), Grosshansdorf, \\ Germany
}

\begin{abstract}
Exacerbations of chronic obstructive pulmonary disease (COPD) are defined as sustained worsening of a patient's condition beyond normal day-to-day variations that is acute in onset, and that may also require a change in medication and/or hospitalization. Exacerbations have a significant and prolonged impact on health status and outcomes, and negative effects on pulmonary function. A significant proportion of exacerbations are unreported and therefore left untreated, leading to a poorer prognosis than those treated. COPD exacerbations are heterogeneous, and various phenotypes have been proposed which differ in biologic basis, prognosis, and response to therapy. Identification of biomarkers could enable phenotype-driven approaches for the management and prevention of exacerbations. For example, several biomarkers of inflammation can help to identify exacerbations most likely to respond to oral corticosteroids and antibiotics, and patients with a frequent exacerbator phenotype, for whom preventative treatment is appropriate. Reducing the frequency of exacerbations would have a beneficial impact on patient outcomes and prognosis. Preventative strategies include modification of risk factors, treatment of comorbid conditions, the use of bronchodilator therapy with long-acting $\beta_{2}$-agonists or long-acting muscarinic antagonists, and inhaled corticosteroids. A better understanding of the mechanisms underlying COPD exacerbations will help to optimize use of the currently available and new interventions for preventing and treating exacerbations.
\end{abstract}

Keywords: COPD, exacerbation, phenotype, biomarker, bronchodilator

\section{Introduction}

Exacerbations of chronic obstructive pulmonary disease (COPD), whether reported/ treated or unreported/untreated, have a detrimental and prolonged impact on patients' health status and outcomes, ${ }^{1-3}$ and have cumulative negative effects on lung function over time. ${ }^{4}$ COPD exacerbations are heterogeneous, varying in severity and phenotype, and thus require careful assessment in order to guide management strategies. ${ }^{5,6}$

Reducing the number of exacerbations that a patient experiences would have a beneficial impact on their daily life, disease outcomes, and prognosis. Strategies to prevent exacerbations include targeting risk factors, addressing comorbid conditions, and bronchodilator therapy with long-acting $\beta_{2}$-agonists (LABAs) or long-acting muscarinic antagonists (LAMAs) (used alone or in combination with each other or with an inhaled corticosteroid [ICS]). ${ }^{7}$

The aim of this article is to provide an overview of the currently accepted consensus definition, an update on the assessment of exacerbations, and to outline the latest evidence for selecting treatment and preventative strategies, including approaches based on specific exacerbation subtypes and risk factors.

\section{What are exacerbations? How do we define exacerbations?}

Exacerbations of COPD can be associated with both respiratory (eg, dyspnea and productive cough) and non-respiratory (eg, fatigue and malaise) symptoms. ${ }^{8}$ The consensus 
definition of an exacerbation is a sustained worsening of the patient's condition from the stable state and beyond normal day-to-day variations that is acute in onset and necessitates a change in medication or hospitalization in a patient with underlying COPD. ${ }^{8}$

COPD exacerbations frequently lead to an increase in health care resource use, according to severity. ${ }^{8,9}$ For example, mild exacerbations can often be managed in the home but may require increased use of reliever medication, such as inhaled bronchodilators, for worsening symptoms, while moderate exacerbations need treatment with antibiotics and/or corticosteroids. Severe exacerbations require hospitalization for advanced monitoring and potential treatments, including assisted ventilation. ${ }^{8}$

\section{Exacerbation phenotypes}

There is heterogeneity in COPD clinical manifestations, outcomes, and responses to treatment. ${ }^{6}$ These differences can be used to classify COPD into specific phenotypes that can be used to guide therapeutic decisions. ${ }^{6}$ Exacerbations in COPD have been shown to be similarly varied, with differing pathology and prognoses, and respond to different management strategies. ${ }^{5,6}$

Many exacerbations of COPD involve bacterial or viral respiratory infections ${ }^{10}$ and, despite resolution of the infection, have been shown to have a sustained effect on health status. $^{2}$

In a study of COPD exacerbation phenotypes, Bafadhel et al identified distinct subtypes that were predominantly related to bacterial or viral infection or elevated eosinophil counts and were associated with $55 \%, 29 \%$, and $28 \%$ of exacerbations, respectively. ${ }^{11}$ These were clinically indistinguishable but could be identified at the biologic level by the use of biomarkers. ${ }^{11}$ Peripheral blood eosinophil count was shown to be a valid biomarker for sputum eosinophilassociated exacerbations (Figure 1). ${ }^{11}$ Unlike bacterial and eosinophilic phenotypes, viral infection was rarely detected in the stable state, suggesting a strong association of viral infections with exacerbations. ${ }^{11}$ Patients with COPD and evidence of eosinophilic airway inflammation respond well to corticosteroid therapy. ${ }^{12}$ Therefore, biomarkers can be informative in identifying phenotypes of COPD that will respond to antibiotics or anti-inflammatory treatment at the onset of an exacerbation. ${ }^{5}$

A "frequent exacerbator" phenotype has been postulated and examined in clinical studies. In the Evaluation of COPD Longitudinally to Identify Predictive Surrogate Endpoints (ECLIPSE) study of COPD exacerbation susceptibility, approximately $20 \%$ of patients with Global initiative for

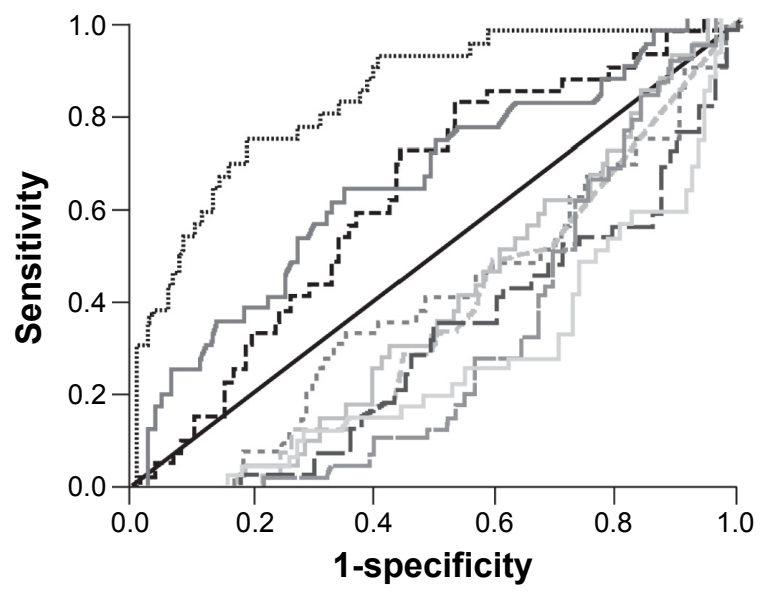

\begin{tabular}{|c|c|}
\hline "mercent blood eosinophils & $==$ Serum C-reactive protein \\
\hline -.. Serum IL-5 & -- Serum IL-6 \\
\hline — Serum CCL17 & - Serum TNF-1B \\
\hline - - Serum VCAM1 & - Serum amyloid A1 \\
\hline - Serum TNF-1B & - Reference line \\
\hline
\end{tabular}

Figure I Receiver operating characteristic curve illustrating that blood eosinophils are a marker of sputum eosinophil-associated exacerbations.

Note: Adapted with permission of the American Thoracic Society. Copyright (C) 2016 American Thoracic Society. Bafadhel M, McKenna S, Terry S, et al. 201 I. Acute exacerbations of chronic obstructive pulmonary disease: identification of biologic clusters and their biomarkers. Am J Respir Crit Care Med. Volume 184(6), Pages 662-67I. The American Journal of Respiratory and Critical Care Medicine is an official journal of the American Thoracic Society."

Abbreviations: IL, interleukin; $\mathrm{CCL}$, chemokine ligand; TNF, tumor necrosis factor; VCAM, vascular cell adhesion molecule.

chronic Obstructive Lung Disease (GOLD) stage 2 disease and as many as $47 \%$ of those with stage 4 disease were classified as "frequent exacerbators" (defined as two or more exacerbations annually). ${ }^{13}$ Risk factors associated with this type of patient include a rapid decline in lung function and respiratory bacterial or viral colonization, although the predictive value of these factors is yet to be ascertained. ${ }^{14}$ A background of persistent airway and systemic inflammation results in slow recovery and poorer outcomes. ${ }^{14}$ Interleukin- 8 and fibrinogen have been proposed as potential biomarkers of the frequent exacerbator phenotype; however, further studies are required for elucidation. ${ }^{15,16}$

\section{How do we assess exacerbations?}

The variety of symptoms that can worsen during an exacerbation of COPD necessitates the use of standardized and validated instruments to evaluate the frequency, severity, and duration of exacerbations. The EXAcerbation of COPD Tool (EXACT), a patient-reported daily diary, has been used in clinical studies to detect and quantify exacerbations. ${ }^{17}$ The tool is based on a set of 14 symptoms that characterize an exacerbation, grouped into subscales of chest symptoms, cough and sputum symptoms, breathlessness symptoms, and 
Table I Symptomatic components of an exacerbation, evaluated using the EXAcerbation of COPD Tool (EXACT) ${ }^{17}$

\begin{tabular}{|c|c|}
\hline \multicolumn{2}{|l|}{ Subscale/item } \\
\hline Chest symptoms & Cough and sputum \\
\hline Chest congested & Coughed today \\
\hline Chest discomfort & Much mucus when coughing \\
\hline \multicolumn{2}{|l|}{ Chest tight } \\
\hline Breathlessness & Other items \\
\hline Breathless today & Difficulty with mucus \\
\hline How breathless today & Weak and tired \\
\hline Shortness of breath with personal care & Sleep disturbed \\
\hline Shortness of breath indoors & Scared/worried \\
\hline Shortness of breath outdoors & \\
\hline
\end{tabular}

constitutional items (Table 1). A recent study showed that the EXACT tool was effective for evaluating exacerbation severity when compared with the London COPD cohort diary. ${ }^{18}$

\section{The impact of exacerbations}

Exacerbations of COPD have a considerable impact on patients' health status ${ }^{2}$ and exercise capacity, ${ }^{19}$ and have a cumulative effect on lung function. ${ }^{4}$

As part of the Gemifloxacin Long-term Outcomes in Bronchitis Exacerbations (GLOBE) study, the time course for recovery of health status in patients with respiratory disease (St George's Respiratory Questionnaire [SGRQ]) and the impact of further exacerbations on time to recovery were assessed over the 6 months following an infective exacerbation of chronic bronchitis. ${ }^{2}$ Following the initial exacerbation, SGRQ scores were worse among the group of patients who experienced subsequent exacerbations during the 6-month follow-up compared with those with no further exacerbation (difference 5.4 units; $P=0.002$ ). ${ }^{2}$ In both groups, the biggest improvement in SGRQ scores occurred within the first 4 weeks after the initial event. ${ }^{2} \mathrm{~A}$ long phase of slow improvement then took place over the 6-month course of the study, with the extent of recovery significantly poorer among patients who experienced further exacerbation. ${ }^{2}$

The short- and long-term impact of exacerbations on exercise capacity was demonstrated by Cote et al. ${ }^{19}$ Patients in this study who experienced exacerbations showed progressive worsening of 6-minute walking distance over time, with a loss of $74 \mathrm{~m}$ reported after 2 years. ${ }^{19}$ In contrast, the control group, comprising patients who did not experience exacerbations during the study period, showed no significant change from baseline. ${ }^{19}$ Reduction in activity associated with exacerbations may lead to patients with COPD becoming housebound. Donaldson et al demonstrated a significant decrease in time spent outdoors $(-0.16$ hour/day/year; $P<0.001)$ by patients with exacerbations, with a significantly more rapid $(P=0.011)$ decline in time spent outdoors evident in those with frequent exacerbations. ${ }^{20}$ Although these effects are modest, these data demonstrate that frequent exacerbations are associated with a higher likelihood of patients with COPD becoming housebound. ${ }^{20}$

Exacerbations of COPD also have a cumulative effect on lung function $\left(\mathrm{FEV}_{1}\right)$. Patients in the 3-year TOward a Revolution in COPD Health (TORCH) study of salmeterol plus fluticasone who experienced 0-1.0 moderate to severe exacerbation per year $(n=1,862)$ had a $37 \%$ faster decline in lung function $(P<0.001)$ than those with no exacerbations $(\mathrm{n}=1,306) .{ }^{4}$ Among those patients who experienced $>1.0$ moderate to severe exacerbation $(\mathrm{n}=1,735)$, the rate of decline in $\mathrm{FEV}_{1}$ was $65 \%$ faster $(P<0.001){ }^{4}$

\section{Reported vs unreported/untreated exacerbations}

Many exacerbations remain unreported and hence untreated by health care professionals, and these also have a substantial impact on patients' health status. ${ }^{1}$ In addition, there is a wide geographic variability in the ratio of reported to unreported exacerbations, which may be due to cultural as well as socioeconomic reasons.

Among a cohort of patients with COPD who had received instruction on reporting worsening symptoms and had regular clinic visits, only $50 \%$ of exacerbations were reported to the clinical team when the patient noticed worsening symptoms on 2 consecutive days, even though there were no differences in major symptoms between reported and unreported (identified from the patient diary card at scheduled clinic visits) events. ${ }^{21}$ During the 6-month, international, randomized Aclidinium To Treat Airway obstruction In COPD patieNts (ATTAIN) trial of aclidinium bromide, a 2.3-fold higher number of exacerbations per patient per year was recorded using the EXACT diary card (1.39 events per patient per year), compared with the number reported based on health care resource use, ie, increased symptoms on $\geq 2$ consecutive days requiring a change in medication ( 0.60 event per patient per year). ${ }^{1}$

Data from the ATTAIN study also demonstrated important differences between reported and unreported exacerbations in terms of impact on health status and recovery post-treatment. ${ }^{1}$ The absolute health status score (SGRQ) was worse, the rate of deterioration in $\mathrm{FEV}_{1}$ was faster, and patients recovered more slowly (EXACT scores) with unreported compared with reported exacerbations (Figure 2). ${ }^{1}$ A reduction in health status score at the time of the exacerbation did not influence whether or not an exacerbation was reported. ${ }^{1}$ The impact of 


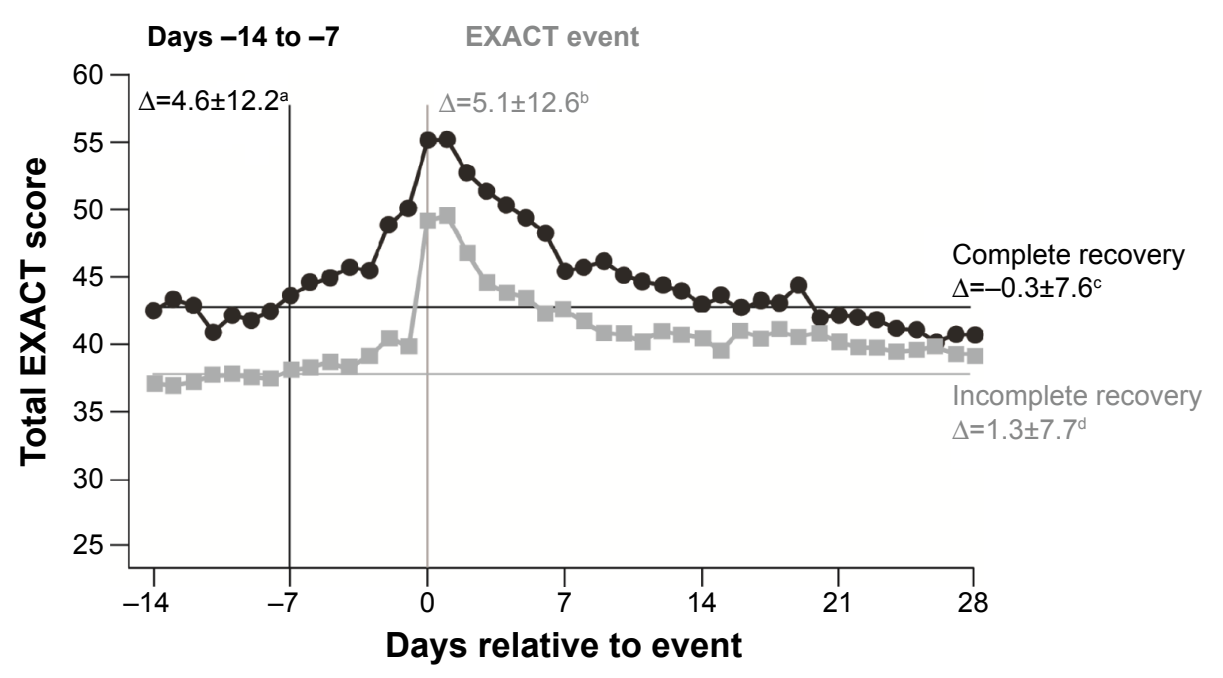

Figure 2 EXAcerbations of COPD Tool (EXACT) scores for reported (identified by health care resource utilization and by EXACT) and unreported (identified by EXACT only) exacerbations.'

Notes: ${ }^{a} P=0.01$; ${ }^{b} P<0.01 ;{ }^{c} P=0.79 ;{ }^{d} P<0.01$. Events presented are those with associated e-diary records for days -14 to -7 . The $\Delta$ values for days -14 to -7 and $E X A C T$ event represent EXACT + health care resource utilization vs EXACT only; the $\Delta$ values for complete recovery for reported exacerbation and incomplete recovery for unreported exacerbations represent days 21 to 28 vs days -14 to -7 .

unreported exacerbations on long-term disease progression is still unknown; however, it is clear that these unreported events have important short- and medium-term consequences on symptoms and health status. ${ }^{1}$

\section{Severe exacerbations}

A long-term follow-up study of a cohort of patients with COPD found that $50 \%$ of patients died within 3.6 years of their first hospitalization for COPD exacerbation. ${ }^{3}$ Following the first severe COPD exacerbation, a period of stable risk was identified between the first and second exacerbations. ${ }^{3}$

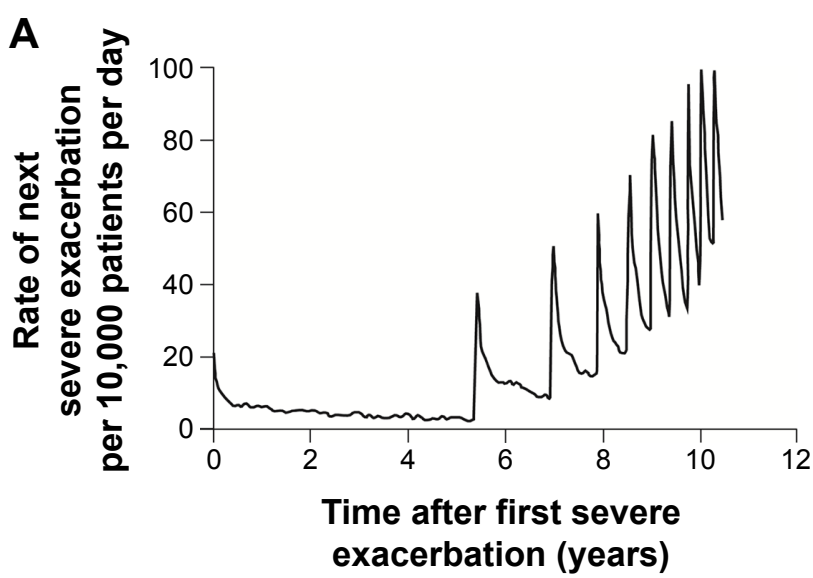

However, each subsequent recurrence of a severe exacerbation requiring hospitalization increased the risk of a subsequent event and death (Figure 3), with subsequent events being of increasing severity. ${ }^{3}$ This highlights the current need for improvement in approaches to both the prevention and treatment of severe exacerbations of COPD.

\section{Management of exacerbations Systemic corticosteroid therapy}

Current evidence-based guidelines for the management of COPD state that in the absence of contraindications, oral

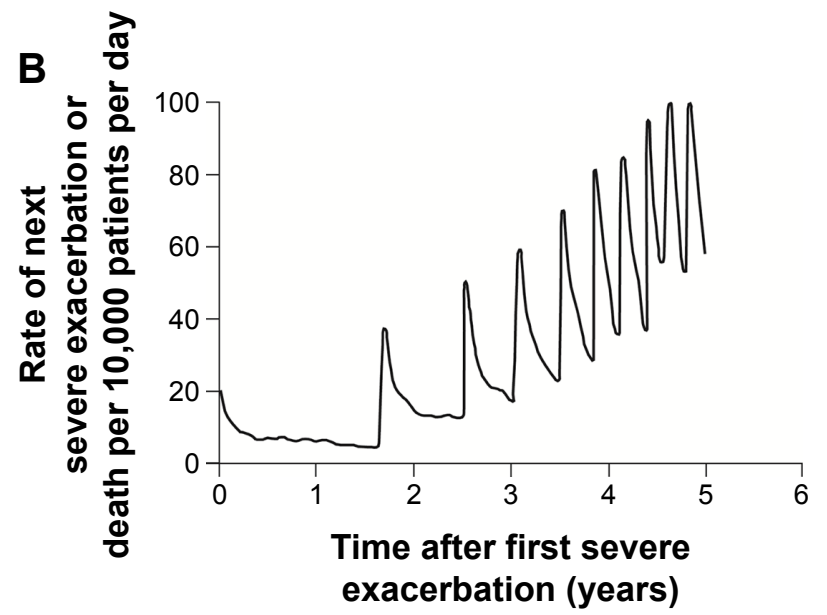

Figure 3 Natural history of COPD in a cohort of 73,106 patients after first hospitalization for a severe exacerbation, showing (A) rate of next severe exacerbation and (B) rate of next severe exacerbation or death per 10,000 patients per day. ${ }^{3}$

Notes: Time between successive events estimated using the median inter-exacerbation times conditional on survival with death as a competing risk (A), or the median inter-exacerbation times as time to next exacerbation or death, whichever occurred first. Reproduced from Thorax, Suissa S, Dell'Aniello S, Ernst P, Volume 67(II), pages 957-963, copyright 2012 with permission from BMJ Publishing Group Ltd. ${ }^{3}$ 
corticosteroids should be used in conjunction with other therapies in all patients admitted to hospital with acute exacerbations. ${ }^{22}$ This recommendation is based on randomized controlled trials, ${ }^{23,24}$ but it is important to note that the effects are relatively small and need to be balanced against the potential for harm. Moreover, there is only limited evidence favoring the use of corticosteroids for patients with severe exacerbations of COPD who require admission to intensive care. ${ }^{25}$ The guidelines for the management of COPD do not make strong recommendations on the use of systemic corticosteroids for exacerbations for outpatients, rather they should be "considered" for outpatients with a significant increase in breathlessness that interferes with daily activities. ${ }^{22,26}$ Overall, there is a lack of data on the use of systemic corticosteroids for the treatment of exacerbations in the outpatient setting, compared with hospitalized patients.

A Cochrane analysis found that systemic corticosteroid use led to fewer treatment failures, a shorter duration of hospitalization, significant lung function $\left(\mathrm{FEV}_{1}\right)$ benefits, and improvements in breathlessness, but with no significant effect on mortality ${ }^{27}$ In addition, there was an increased risk of an adverse event, in particular hyperglycemia, associated with systemic corticosteroid use. ${ }^{27}$ The 2015 update to the GOLD strategy document recommends treatment with oral prednisone $40 \mathrm{mg}$ per day for only 5 days for hospitalized patients. ${ }^{26}$ This recommendation is based on the REDuction in the Use of Corticosteroids in Exacerbated COPD (REDUCE) study, which demonstrated that, in patients presenting to the emergency department with an acute exacerbation of COPD, a 5-day regimen with oral prednisone $40 \mathrm{mg}$ is non-inferior to 14 days' treatment, with regard to re-exacerbation within 6 months' follow-up. ${ }^{28}$ However, there were no significant differences in glucocorticoid-related, short-term adverse effects between the treatment groups. ${ }^{28}$ It is also likely that lower doses of systemic steroids are associated with fewer side effects and a better benefit/risk profile than higher doses in patients hospitalized in intensive care units. ${ }^{29}$

A phenotype-guided treatment approach could be appropriate to better target the use of corticosteroids in patients to prevent and treat COPD exacerbations. The presence of an elevated sputum eosinophil count in patients with stable COPD has been associated with a good response to prednisolone. ${ }^{12}$ As such, a blood eosinophil count $>2 \%$ has been suggested as an easily obtainable biomarker for predicting effectiveness of oral corticosteroids in patients with exacerbations. ${ }^{5}$ A recent meta-analysis of outcomes with placebo and prednisolone showed that prednisolone reduced treatment failure rates at 30 days from $66 \%$ to $11 \%{ }^{5}$ In contrast, prednisolone was not effective in patients with a blood eosinophil count of $\leq 2 \%$, and one study suggested that treatment failure rates were significantly worse with antibiotics and prednisolone compared with antibiotics and placebo. ${ }^{30}$ Although confirmation of these findings is required, they indicate that blood eosinophil count could potentially be used as a biomarker to direct corticosteroid therapy for exacerbations and could help avoid unnecessary exposure to systemic corticosteroids. Fractional excretion of nitric oxide has been used to identify airway inflammation in other respiratory conditions, and preliminary studies have demonstrated that this could be used as a potential marker of response to corticosteroids in patients with COPD. ${ }^{31-33}$

\section{Antibiotic therapy}

Approximately 50\% of COPD exacerbations are associated with detection of bacteria in the sputum, ${ }^{11}$ and current guidelines recommend antibiotic therapy when patients present with the three cardinal symptoms (increased dyspnea, sputum volume, and sputum purulence), or with increased sputum purulence and one other cardinal symptom. ${ }^{26}$

A meta-analysis of antibiotic use in COPD exacerbations revealed inconsistent effects, with more pronounced positive effects on treatment success in hospitalized patients vs outpatients, but no significant effects on mortality or length of hospital stay. ${ }^{34}$ However, a randomized, placebo-controlled trial of hospitalized patients who needed mechanical ventilation for COPD exacerbations found that mortality significantly increased from $4 \%$ to $22 \%$ in those patients randomized to no antibiotic..$^{35}$ Therefore, antibiotics should not be withheld in patients with severe exacerbations who require ventilator support.

C-reactive protein (CRP) is a potentially useful biomarker for predicting which exacerbations may benefit from antibiotic therapy and for selecting those that might resolve without antibiotic intervention. ${ }^{36}$ In patients with exacerbations and CRP levels $>50 \mathrm{mg} / \mathrm{L}$, a significantly higher rate of clinical success for doxycycline treatment was demonstrated vs placebo. ${ }^{36}$ The same study concluded that procalcitonin may not be sufficiently sensitive for use as a biomarker for response to antibiotics in patients with COPD exacerbations. ${ }^{36}$ Therefore, the use of CRP as a biomarker could help to avoid unnecessary use of antibiotic therapy that can lead to adverse effects and development of bacterial resistance. ${ }^{37}$

\section{Non-invasive ventilation and oxygen therapy}

Non-invasive ventilation improves gas exchange by providing ventilator support through the upper airway using a mask, and is recommended for severe COPD exacerbations in 
patients with respiratory acidosis (arterial $\mathrm{pH} \leq 7.35$ ) when added to standard therapy. ${ }^{22,26}$ Early use of this therapy following hospitalization has been shown to reduce the need for intubation and improves survival in patients with COPD in a randomized clinical trial. ${ }^{38,39}$ However, there is some controversy on this subject because another recent study did not detect any benefit of non-invasive ventilation. ${ }^{40}$

Oxygen therapy has also been shown to reduce hypoxia associated with exacerbations of COPD; however, careful titration of oxygen levels is crucial, particularly in patients at risk of hypercapnic respiratory failure. ${ }^{41}$

\section{Home management}

Although exacerbations have a considerable clinical impact, some patients could be safely treated at home. ${ }^{22}$ This approach would reduce demand for hospital beds and would also take patients' preferences for home- or hospital-based treatment into consideration. ${ }^{22,42}$ Current guidance acknowledges however that it may be difficult to determine which patients home management is appropriate for, although resources available and poor prognostic indicators (eg, acidosis) will influence the decision. ${ }^{22}$

Roche et al developed a scoring system, based on variables at admission to hospital for COPD exacerbation (age, exacerbation severity, and dyspnea), that may be useful for predicting risk of death and requirement for post-hospital support. ${ }^{43} \mathrm{~A}$ recent independent study by the same authors suggests that this score may prove useful in clinical practice, but further validation is still necessary ${ }^{44} \mathrm{~A}$ Cochrane review, evaluating early hospital discharge combined with a domiciliary respiratory nurse for managing acute COPD exacerbations as an alternative to hospitalization, found that hospital re-admissions were reduced with the "hospital at home" approach (risk ratio $0.76 ; P=0.04$ ). ${ }^{42}$ Furthermore, there were early indications for reduced risk of mortality (risk ratio 0.66 ; $P=0.07) .{ }^{42}$ Evidence is lacking though for a strongly positive association between the "hospital at home" approach and other outcomes (lung function, patient satisfaction, quality of life, and cost-effectiveness).$^{42}$ Furthermore, only a minority (25\%) of patients were eligible for the "hospital at home" approach, based on lung function, comorbidities, and other factors (eg, confusion). ${ }^{42}$

\section{Preventing exacerbations}

There is evidence that COPD exacerbations cluster together, and a high-risk period for recurrence has been identified in the first 8 weeks following an initial event. ${ }^{45}$ This may have important implications for preventative strategies.

\section{Risk factors as targets for intervention}

Risk factors for COPD are also risk factors for the frequency and severity of exacerbations, and as such, are potential targets for intervention. These include smoking cessation, prevention of respiratory infections, and avoiding a rapid decline in lung function. ${ }^{14}$ Decreased $\mathrm{FEV}_{1}$ in particular is associated with increased symptoms and heightened inflammatory responses, thus targeting lung mechanics may alter the risk of an exacerbation. ${ }^{46}$

\section{Inhaled corticosteroids}

ICS is commonly prescribed to patients with COPD, with the primary goal of reducing exacerbations. There is consistent evidence that ICS treatment reduces exacerbation frequency by $\sim 25 \%$ either when prescribed alone or in combination with a LABA. ${ }^{47,48}$ Current guidelines recommend ICS therapy in patients with two or more COPD exacerbations in the last year, one severe exacerbation, or impaired lung function such that an exacerbation risk is deemed to be present. ${ }^{26}$ Traditionally, a high dose of ICS (eg, fluticasone dipropionate $500 \mu \mathrm{g}$ bid) is prescribed; however, there is little high-quality information available on the dose-response relationship. A study of once-daily fluticasone furoate, at a dosage of 50-100 $\mu \mathrm{g}$ daily in addition to vilanterol, demonstrated a progressive treatment benefit, with no apparent benefit above this dose. ${ }^{49}$ The potential for ICS to cause pneumonia is a concern; this is a function of dose and duration of treatment. ${ }^{50}$ Currently, there is a great deal of interest in the possibility that this risk might be mitigated using the blood eosinophil count as a biomarker of likely response to ICS. Two studies have shown that the risk of exacerbation and the benefits of ICS increase progressively as the blood eosinophil count increases above $2 \%$ (equivalent to a count of $0.15 \times 10^{9} / \mathrm{L}$ ), whereas patients with a blood eosinophil count $<2 \%$ had little evidence of benefit from ICS. ${ }^{51,52}$ However, the elevated risk of pneumonia associated with ICS use was independent of eosinophil count; therefore, patients with a blood eosinophil count of $<2 \%$ had minimal benefit from the ICS but increased risk of pneumonia. ${ }^{51}$

\section{Bronchodilator treatment}

The nature of the exacerbation and the COPD phenotype dictate the extent of mechanical and anti-inflammatory intervention required; patients with more mucus and airway/ lung function impairment are more likely to benefit from anti-inflammatory therapy, whereas patients with greater mechanical impairment are likely to benefit from bronchodilator therapy, even without corticosteroids. ${ }^{53}$ 
The Prevention Of Exacerbations with Tiotropium in COPD (POET) study showed that long-acting bronchodilator therapy with the anti-cholinergic drug tiotropium was superior to a LABA, salmeterol, in preventing exacerbations in patients with moderate to severe COPD at risk of exacerbation. ${ }^{54}$ Time to first exacerbation was increased ( 187 vs 145 days; hazard ratio $0.83 ; P<0.001$ ), and the annual number of moderate or severe exacerbations was reduced ( 0.64 vs $0.72 ; P=0.02)$ with tiotropium compared with salmeterol. ${ }^{54}$ The concomitant use of ICS showed no effect on these outcomes. ${ }^{54}$ Interestingly, the response to salmeterol can be influenced by the $\beta 2$-adrenergic receptor genotype. ${ }^{55}$ Patients with the Arg16Arg genotype had a reduced risk of exacerbation in response to salmeterol than those with the Arg16Gly and Gly16Gly genotypes. ${ }^{55}$

The ATTAIN study investigated the efficacy of the inhaled LAMA aclidinium in moderate to severe COPD. ${ }^{1}$ Regardless of whether COPD exacerbations were reported (recorded by health care resource utilization) or unreported (recorded by EXACT), aclidinium treatment demonstrated a similar clinical benefit, instigating a $29 \%-33 \%$ reduction in annualized rates of exacerbation per patient per year. ${ }^{1}$

In the SPARK study, the efficacy of the dual LAMA/ LABA glycopyrronium/indacaterol was compared with glycopyrronium and open-label tiotropium in patients with severe or very severe COPD. ${ }^{56}$ Approximately $75 \%$ of patients were also using a concomitant ICS. Glycopyrronium/indacaterol reduced the annualized rate of COPD exacerbations (all severities) compared with glycopyrronium or tiotropium monotherapy, indicating that combining a $\beta 2$-agonist with an anti-cholinergic agent reduces exacerbation frequency. ${ }^{56} \mathrm{This}$ dual bronchodilation approach may be clinically beneficial for patients with severe disease, and may circumvent the genetic variability that renders patients less susceptible to single agents. ${ }^{56}$

The annual incidence of moderate or severe exacerbations, systemic corticosteroid prescriptions, and hospitalizations were reduced significantly in the TORCH study with both the $\beta 2$-agonist salmeterol and corticosteroid fluticasone. ${ }^{48}$ The effects were greater in patients who administered the drugs in combination, suggesting that multiple underlying factors may be involved in determining response to therapy (Figure 4). ${ }^{48}$ However, the recently published Withdrawal of Inhaled Steroids During Optimized bronchodilator Management (WISDOM) study specifically investigated impact on exacerbation frequency caused by the withdrawal of ICS and found that ICS use did not alter the risk of moderate to severe COPD exacerbations. ${ }^{57}$ These results should be

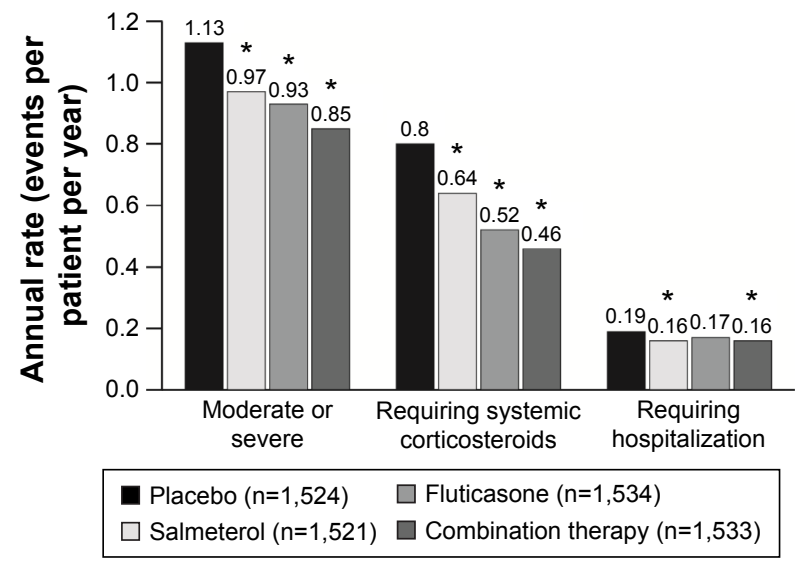

Figure 4 Annual rate of exacerbations, systemic corticosteroid prescriptions, and hospitalizations in a randomized, placebo-controlled trial of combination therapy with a long-acting $\beta$-agonist and inhaled corticosteroid in patients with COPD.

Notes: *Significant difference vs placebo at the 0.05 significance level. From The New England Journal of Medicine, Calverley PM, Anderson JA, Celli B, et al, Salmeterol and fluticasone propionate and survival in chronic obstructive pulmonary disease, Volume 356(8), Pages 775-789. Copyright (C) 2007 Massachusetts Medical Society. Reprinted with permission from Massachusetts Medical Society. ${ }^{48}$

interpreted with caution, because only those patients who had at least one exacerbation in the previous year met the recruitment criteria, meaning that those responding poorly to ICS were more likely to be represented in the study population.

\section{Other approaches to reduce exacerbation risk}

In addition to bronchodilators, other classes of drugs have been shown to reduce exacerbation risk in specific subsets of patients with COPD. A randomized trial of the macrolide azithromycin, taken daily for 1 year in addition to usual therapy, demonstrated a significant reduction in the risk of exacerbations in patients with COPD at increased risk of exacerbation. ${ }^{58}$ This effect was greatest in the subgroup of patients requiring both antibiotic and corticosteroid treatment, and in patients who were non- or ex-smokers. ${ }^{59}$ Similarly, a study of the oral anti-inflammatory agent roflumilast, a phosphodiesterase-4 inhibitor, has demonstrated a reduction in exacerbations frequency in patients with severe COPD and a history of exacerbations. ${ }^{60}$ Two Chinese clinical studies showed that $\mathrm{N}$-acetylcysteine and the mucolytic agent carbocisteine, both of which have antioxidant and anti-inflammatory properties, may reduce the frequency of exacerbations of COPD in Chinese patients. ${ }^{61,62}$

There is evidence that pneumococcal and annual influenza vaccinations reduce the risk of exacerbation and hospitalization in patients with COPD, and it is recommended that these are offered to patients with COPD. . $22,26,63,64^{2}$ 


\section{Treating comorbid conditions}

Comorbidities of COPD, such as cardiovascular disease, gastroesophageal reflux disease, depression, and osteoporosis, are associated with increased susceptibility to exacerbations and can also contribute to how COPD develops. ${ }^{14}$ Cardiovascular disease is the most common group of comorbidities, with ischemic heart disease estimated to affect around $20 \%$ of patients with COPD. ${ }^{14}$ Severe COPD exacerbations may involve underlying comorbidities, particularly endocrine and cardiovascular conditions. For example, systemic inflammation and elevated CRP, both features of COPD, have been associated with increased cardiovascular risk. ${ }^{14}$ Patients with severe airflow obstruction have even poorer cardiac outcomes than those with systemic inflammation; however, those with both impaired lung function and systemic inflammation have a significantly worse cardiovascular outcome in terms of the cardiac infarction injury score. ${ }^{65}$

Preventative strategies should therefore consider these comorbid conditions. Although there is sparse evidence from randomized trials demonstrating that treating comorbidities improves COPD, several treatment approaches have shown a benefit in observational studies. Statin therapy may help to improve outcomes in patients with COPD and peripheral arterial disease ${ }^{66}$ and other cardiovascular comorbidities. ${ }^{67}$ However, a recent study of simvastatin in patients with moderate to severe COPD without metabolic/cardiovascular indication for statins did not observe any reduction in COPD exacerbations. ${ }^{68}$ There is evidence suggesting that the use of angiotensin-converting enzyme inhibitors, angiotensin receptor blockers, and beta blockers may reduce mortality in patients with COPD and cardiovascular comorbidities. ${ }^{69,70}$

Given the prevalence of cardiovascular comorbidities among patients with COPD, cardiovascular safety of COPD therapy also needs to be considered. For example, in a pooled analysis of long-term studies in COPD, the oral antiinflammatory agent roflumilast has not been associated with major cardiovascular events in long-term studies. ${ }^{71}$

A better understanding of the mechanisms triggering exacerbations will help to determine the optimal use of preventative strategies in future.

\section{Conclusion}

Exacerbations of COPD have a substantial impact on health status and cumulative effects on lung function. Many exacerbations are unreported, which not only underestimates their incidence, but may also lead to under-treatment and poorer recovery. Distinct COPD exacerbation subtypes have been proposed, which may differ in prognosis and response to treatment. The management of COPD should involve phenotype-directed strategies, and efforts have been made to identify biomarkers that could help guide treatment. In addition, efforts to prevent exacerbations should aim to reduce risk factors and manage comorbid conditions. Understanding the mechanisms by which COPD exacerbations occur may determine the best course of preventative strategy and lead to development of novel interventions.

\section{Acknowledgments}

Medical writing support was provided by Kirsteen Munn on behalf of Complete Medical Communications, funded by Almirall S.A., Barcelona, Spain.

\section{Disclosure}

Professor Pavord has previously received speaker's fees and honoraria from Aerorine, Almirall, AstraZeneca, Boehringer Ingelheim, Dey, GlaxoSmithKline, Napp, Novartis, and Respivert. Professor Jones has previously received speaker fees from and has served on advisory boards for Almirall, AstraZeneca, Chiesi, GlaxoSmithKline, Novartis, Roche, and Spiration, and has received research grants from GlaxoSmithKline. All fees were contracted via his institution. Professor Burgel has previously received lecture fees and honoraria from, and served on advisory boards for, Air Liquide, Almirall, AstraZeneca, Boehringer Ingelheim, Chiesi, GlaxoSmithKline, Novartis, and Pfizer, and has received research grants from Boehringer Ingelheim and Pfizer. Professor Rabe has consulted for, participated in advisory board meetings with, and received lecture fees from Almirall, AstraZeneca, Boehringer Ingelheim, Chiesi, Pfizer, Novartis, Takeda, Merck Sharp \& Dohme, and GlaxoSmithKline. Professor Rabe has also received grants from Novartis, AstraZeneca, Boehringer Ingelheim, Hoffmann-La Roche, Altana, and GlaxoSmithKline.

\section{References}

1. Jones PW, Lamarca R, Chuecos F, et al. Characterisation and impact of reported and unreported exacerbations: results from ATTAIN. Eur Respir J. 2014;44(5):1156-1165.

2. Spencer S, Jones PW. Time course of recovery of health status following an infective exacerbation of chronic bronchitis. Thorax. 2003;58(7):589-593.

3. Suissa S, Dell'Aniello S, Ernst P. Long-term natural history of chronic obstructive pulmonary disease: severe exacerbations and mortality. Thorax. 2012;67(11):957-963.

4. Celli BR, Thomas NE, Anderson JA, et al. Effect of pharmacotherapy on rate of decline of lung function in chronic obstructive pulmonary disease: results from the TORCH study. Am J Respir Crit Care Med. 2008; 178(4):332-338. 
5. Bafadhel M, McKenna S, Terry S, et al. Blood eosinophils to direct corticosteroid treatment of exacerbations of chronic obstructive pulmonary disease: a randomized placebo-controlled trial. Am J Respir Crit Care Med. 2012;186(1):48-55.

6. Han MK, Agusti A, Calverley PM, et al. Chronic obstructive pulmonary disease phenotypes: the future of COPD. Am J Respir Crit Care Med. 2010;182(5):598-604.

7. Vestbo J, Hurd SS, Agustí AG, et al. Global strategy for the diagnosis, management, and prevention of chronic obstructive pulmonary disease: GOLD Executive Summary. Am J Respir Crit Care Med. 2013;187(4):347-365.

8. Rodriguez-Roisin R. Toward a consensus definition for COPD exacerbations. Chest. 2000;117(5 Suppl 2):398S-401S.

9. Burge S, Wedzicha JA. COPD exacerbations: definitions and classifications. Eur Respir J. 2003;21(41 Suppl):46s-53s

10. Sethi S, Murphy TF. Infection in the pathogenesis and course of chronic obstructive pulmonary disease. N Engl J Med. 2008;359(22):2355-2365.

11. Bafadhel M, McKenna S, Terry S, et al. Acute exacerbations of chronic obstructive pulmonary disease: identification of biologic clusters and their biomarkers. Am J Respir Crit Care Med. 2011;184(6):662-671.

12. Brightling CE, Monteiro W, Ward R, et al. Sputum eosinophilia and shortterm response to prednisolone in chronic obstructive pulmonary disease: a randomised controlled trial. Lancet. 2000;356(9240):1480-1485.

13. Hurst JR, Vestbo J, Anzueto A, et al. Susceptibility to exacerbation in chronic obstructive pulmonary disease. N Engl J Med. 2010;363(12):1128-1138.

14. Wedzicha JA, Brill SE, Allinson JP, Donaldson GC. Mechanisms and impact of the frequent exacerbator phenotype in chronic obstructive pulmonary disease. BMC Med. 2013;11:181.

15. Bhowmik A, Seemungal TA, Sapsford RJ, Wedzicha JA. Relation of sputum inflammatory markers to symptoms and lung function changes in COPD exacerbations. Thorax. 2000;55(2):114-120.

16. Groenewegen KH, Postma DS, Hop WC, Wielders PL, Schlosser NJ, Wouters EF. Increased systemic inflammation is a risk factor for COPD exacerbations. Chest. 2008;133(2):350-357.

17. Jones PW, Chen WH, Wilcox TK, Sethi S, Leidy NK. Characterizing and quantifying the symptomatic features of COPD exacerbations. Chest. 2011;139(6):1388-1394.

18. Mackay AJ, Donaldson GC, Patel AR, Singh R, Kowlessar B, Wedzicha JA. Detection and severity grading of COPD exacerbations using the exacerbations of Chronic Obstructive Pulmonary Disease Tool (EXACT). Eur Respir J. 2014;43(3):735-744.

19. Cote CG, Dordelly LJ, Celli BR. Impact of COPD exacerbations on patient-centered outcomes. Chest. 2007;131(3):696-704.

20. Donaldson GC, Wilkinson TM, Hurst JR, Perera WR, Wedzicha JA. Exacerbations and time spent outdoors in chronic obstructive pulmonary disease. Am J Respir Crit Care Med. 2005;171(5):446-452.

21. Seemungal TA, Donaldson GC, Paul EA, Bestall JC, Jeffries DJ, Wedzicha JA. Effect of exacerbation on quality of life in patients with chronic obstructive pulmonary disease. Am J Respir Crit Care Med. 1998; 157(5 Pt 1):1418-1422.

22. National Institute for Health and Care Excellence [homepage on the Internet]. NICE Clinical Guideline 101, Management of chronic obstructive pulmonary disease in adults in primary and secondary care (partial update) [updated 2010]. Available from: http://www.nice.org. uk/guidance/CG101. Accessed October 21, 2015.

23. Davies L, Angus RM, Calverley PM. Oral corticosteroids in patients admitted to hospital with exacerbations of chronic obstructive pulmonary disease: a prospective randomised controlled trial. Lancet. 1999; 354(9177):456-460.

24. Niewoehner DE, Erbland ML, Deupree RH, et al. Effect of systemic glucocorticoids on exacerbations of chronic obstructive pulmonary disease. Department of Veterans Affairs Cooperative Study Group. N Engl J Med. 1999;340(25):1941-1947.

25. Abroug F, Krishnan JA. What is the right dose of systemic corticosteroids for intensive care unit patients with chronic obstructive pulmonary disease exacerbations? A question in search of a definitive answer. Am J Respir Crit Care Med. 2014;189(9):1014-1016.
26. Global Initiative for Chronic Obstructive Lung Disease [homepage on the Internet]. Global strategy for the diagnosis, management, and prevention of chronic obstructive pulmonary disease [updated 2015]. Available from: http://www.goldcopd.org/uploads/users/files/ GOLD_Report_2015_Feb18.pdf. Accessed October 21, 2015.

27. Walters JA, Tan DJ, White CJ, Gibson PG, Wood-Baker R, Walters EH. Systemic corticosteroids for acute exacerbations of chronic obstructive pulmonary disease. Cochrane Database Syst Rev. 2014;9:CD001288.

28. Leuppi JD, Schuetz P, Bingisser R, et al. Short-term vs conventional glucocorticoid therapy in acute exacerbations of chronic obstructive pulmonary disease: the REDUCE randomized clinical trial. JAMA. 2013;309(21):2223-2231.

29. Kiser TH, Allen RR, Valuck RJ, Moss M, Vandivier RW. Outcomes associated with corticosteroid dosage in critically ill patients with acute exacerbations of chronic obstructive pulmonary disease. Am J Respir Crit Care Med. 2014;189(9):1052-1064.

30. Bafadhel M, Davies L, Calverley PM, Aaron SD, Brightling CE, Pavord ID. Blood eosinophil guided prednisolone therapy for exacerbations of COPD: a further analysis. Eur Respir J. 2014;44(3): 789-791.

31. Donohue JF, Herje N, Crater G, Rickard K. Characterization of airway inflammation in patients with COPD using fractional exhaled nitric oxide levels: a pilot study. Int J Chron Obstruct Pulmon Dis. 2014; 9:745-751.

32. Dummer JF, Epton MJ, Cowan JO, et al. Predicting corticosteroid response in chronic obstructive pulmonary disease using exhaled nitric oxide. Am J Respir Crit Care Med. 2009;180(9):846-852.

33. Kunisaki KM, Rice KL, Janoff EN, Rector TS, Niewoehner DE. Exhaled nitric oxide, systemic inflammation, and the spirometric response to inhaled fluticasone propionate in severe chronic obstructive pulmonary disease: a prospective study. Ther Adv Respir Dis. 2008;2(2): $55-64$

34. Vollenweider DJ, Jarrett H, Steurer-Stey CA, Garcia-Aymerich J, Puhan MA. Antibiotics for exacerbations of chronic obstructive pulmonary disease. Cochrane Database Syst Rev. 2012;12:CD010257.

35. Nouira S, Marghli S, Belghith M, Besbes L, Elatrous S, Abroug F. Once daily oral ofloxacin in chronic obstructive pulmonary disease exacerbation requiring mechanical ventilation: a randomised placebocontrolled trial. Lancet. 2001;358(9298):2020-2025.

36. Daniels JM, Schoorl M, Snijders D, et al. Procalcitonin vs C-reactive protein as predictive markers of response to antibiotic therapy in acute exacerbations of COPD. Chest. 2010;138(5):1108-1115.

37. Herath SC, Poole P. Prophylactic antibiotic therapy for chronic obstructive pulmonary disease (COPD). Cochrane Database Syst Rev. 2013 11:CD009764.

38. Plant PK, Owen JL, Elliott MW. Early use of non-invasive ventilation for acute exacerbations of chronic obstructive pulmonary disease on general respiratory wards: a multicentre randomised controlled trial. Lancet. 2000;355(9219):1931-1935.

39. Plant PK, Owen JL, Parrott S, Elliott MW. Cost effectiveness of ward based non-invasive ventilation for acute exacerbations of chronic obstructive pulmonary disease: economic analysis of randomised controlled trial. BMJ. 2003;326(7396):956.

40. Struik FM, Sprooten RT, Kerstjens HA, et al. Nocturnal non-invasive ventilation in COPD patients with prolonged hypercapnia after ventilatory support for acute respiratory failure: a randomised, controlled, parallel-group study. Thorax. 2014;69(9):826-834.

41. Brill SE, Wedzicha JA. Oxygen therapy in acute exacerbations of chronic obstructive pulmonary disease. Int J Chron Obstruct Pulmon Dis. 2014; 9:1241-1252.

42. Jeppesen E, Brurberg KG, Vist GE, et al. Hospital at home for acute exacerbations of chronic obstructive pulmonary disease. Cochrane Database Syst Rev. 2012;5:CD003573.

43. Roche N, Zureik M, Soussan D, Neukirch F, Perrotin D. Predictors of outcomes in COPD exacerbation cases presenting to the emergency department. Eur Respir J. 2008;32(4):953-961. 
44. Roche N, Chavaillon JM, Maurer C, Zureik M, Piquet J. A clinical in-hospital prognostic score for acute exacerbations of COPD. Respir Res. 2014;15:99.

45. Hurst JR, Donaldson GC, Quint JK, Goldring JJ, Baghai-Ravary R, Wedzicha JA. Temporal clustering of exacerbations in chronic obstructive pulmonary disease. Am J Respir Crit Care Med. 2009;179(5): 369-374.

46. Donaldson GC, Wedzicha JA. COPD exacerbations. 1: Epidemiology. Thorax. 2006;61(2):164-168.

47. Burge PS, Calverley PM, Jones PW, Spencer S, Anderson JA, Maslen TK. Randomised, double blind, placebo controlled study of fluticasone propionate in patients with moderate to severe chronic obstructive pulmonary disease: the ISOLDE trial. $B M J$. 2000;320(7245):1297-1303.

48. Calverley PM, Anderson JA, Celli B, et al. Salmeterol and fluticasone propionate and survival in chronic obstructive pulmonary disease. N Engl J Med. 2007;356(8):775-789.

49. Dransfield MT, Bourbeau J, Jones PW, et al. Once-daily inhaled fluticasone furoate and vilanterol versus vilanterol only for prevention of exacerbations of COPD: two replicate double-blind, parallel-group, randomised controlled trials. Lancet Respir Med. 2013;1(3):210-223.

50. Suissa S, Patenaude V, Lapi F, Ernst P. Inhaled corticosteroids in COPD and the risk of serious pneumonia. Thorax. 2013;68(11):1029-1036.

51. Pascoe S, Locantore N, Dransfield MT, Barnes NC, Pavord ID. Blood eosinophil counts, exacerbations, and response to the addition of inhaled fluticasone furoate to vilanterol in patients with chronic obstructive pulmonary disease: a secondary analysis of data from two parallel randomised controlled trials. Lancet Respir Med. 2015;3(6):435-442.

52. Siddiqui SH, Guasconi A, Vestbo J, et al. Blood eosinophils: a biomarker of response to extrafine beclomethasone/formoterol in chronic obstructive pulmonary disease. Am J Respir Crit Care Med. 2015; 192(4):523-525.

53. Gonem S, Raj V, Wardlaw AJ, Pavord ID, Green R, Siddiqui S. Phenotyping airways disease: an A to E approach. Clin Exp Allergy. 2012; 42(12):1664-1683.

54. Vogelmeier C, Hederer B, Glaab T, et al. Tiotropium versus salmeterol for the prevention of exacerbations of COPD. $N$ Engl J Med. 2011; 364(12):1093-1103.

55. Rabe KF, Fabbri LM, Israel E, et al. Effect of ADRB2 polymorphisms on the efficacy of salmeterol and tiotropium in preventing COPD exacerbations: a prespecified substudy of the POET-COPD trial. Lancet Respir Med. 2014;2(1):44-53.

56. Wedzicha JA, Decramer M, Ficker JH, et al. Analysis of chronic obstructive pulmonary disease exacerbations with the dual bronchodilator QVA149 compared with glycopyrronium and tiotropium (SPARK): a randomised, double-blind, parallel-group study. Lancet Respir Med. 2013;1(3):199-209.

57. Magnussen H, Disse B, Rodriguez-Roisin R, et al. Withdrawal of inhaled glucocorticoids and exacerbations of COPD. N Engl J Med. 2014; 371(14):1285-1294.
58. Albert RK, Connett J, Bailey WC, et al. Azithromycin for prevention of exacerbations of COPD. N Engl J Med. 2011;365(8):689-698.

59. Han MK, Tayob N, Murray S, et al. Predictors of chronic obstructive pulmonary disease exacerbation reduction in response to daily azithromycin therapy. Am J Respir Crit Care Med. 2014;189(12):1503-1508.

60. Calverley PM, Rabe KF, Goehring UM, Kristiansen S, Fabbri LM, Martinez FJ. Roflumilast in symptomatic chronic obstructive pulmonary disease: two randomised clinical trials. Lancet. 2009;374(9691): 685-694.

61. Zheng JP, Kang J, Huang SG, et al. Effect of carbocisteine on acute exacerbation of chronic obstructive pulmonary disease (PEACE Study): a randomised placebo-controlled study. Lancet. 2008;371(9629): 2013-2018

62. Zheng JP, Wen FQ, Bai CX, et al. Twice daily N-acetylcysteine $600 \mathrm{mg}$ for exacerbations of chronic obstructive pulmonary disease (PANTHEON): a randomised, double-blind placebo-controlled trial. Lancet Respir Med. 2014;2(3):187-194.

63. Poole PJ, Chacko E, Wood-Baker RW, Cates CJ. Influenza vaccine for patients with chronic obstructive pulmonary disease. Cochrane Database Syst Rev. 2000;4:CD002733.

64. Walters JA, Smith S, Poole P, Granger RH, Wood-Baker R. Injectable vaccines for preventing pneumococcal infection in patients with chronic obstructive pulmonary disease. Cochrane Database Syst Rev. 2010;11:CD001390.

65. Sin DD, Man SF. Why are patients with chronic obstructive pulmonary disease at increased risk of cardiovascular diseases? The potential role of systemic inflammation in chronic obstructive pulmonary disease. Circulation. 2003;107(11):1514-1519.

66. van Gestel YR, Hoeks SE, Sin DD, et al. Effect of statin therapy on mortality in patients with peripheral arterial disease and comparison of those with versus without associated chronic obstructive pulmonary disease. Am J Cardiol. 2008;102(2):192-196.

67. Young RP, Hopkins RJ. Update on the potential role of statins in chronic obstructive pulmonary disease and its co-morbidities. Expert Rev Respir Med. 2013;7(5):533-544.

68. Criner GJ, Connett JE, Aaron SD, et al. Simvastatin for the prevention of exacerbations in moderate-to-severe COPD. $N$ Engl J Med. 2014; 370(23):2201-2210.

69. Mortensen EM, Copeland LA, Pugh MJ, et al. Impact of statins and ACE inhibitors on mortality after COPD exacerbations. Respir Res. 2009; $10: 45$.

70. Quint JK, Herrett E, Bhaskaran K, et al. Effect of beta blockers on mortality after myocardial infarction in adults with COPD: population based cohort study of UK electronic healthcare records. $B M J$. 2013;347:f6650.

71. White WB, Cooke GE, Kowey PR, et al. Cardiovascular safety in patients receiving roflumilast for the treatment of COPD. Chest. 2013; 144(3):758-765.
International Journal of COPD

\section{Publish your work in this journal}

The International Journal of COPD is an international, peer-reviewed journal of therapeutics and pharmacology focusing on concise rapid reporting of clinical studies and reviews in COPD. Special focus is given to the pathophysiological processes underlying the disease, intervention programs, patient focused education, and self management protocols.
Dovepress

This journal is indexed on PubMed Central, MedLine and CAS. The manuscript management system is completely online and includes a very quick and fair peer-review system, which is all easy to use. Visit http://www.dovepress.com/testimonials.php to read real quotes from published authors. 